\title{
Healthcare-Associated Infection Symposium report
}

\author{
Held on 2 February at the Royal College of Physicians of Edinburgh \\ B Edwards \\ Microbiology Specialty Registrar (ST2), Aberdeen Royal Infirmary, Aberdeen, UK
}

DECLARATION OF INTERESTS No conflict of interests declared.

\author{
Correspondence to B Edwards, \\ Microbiology Department, Aberdeen \\ Royal Infirmary, Foresterhill Road, \\ Aberdeen AB25 2ZN, UK
}

tel. +44 (0) I 22455495 I

e-mail beckyedwards@nhs.net
The profile of healthcare-associated infection ( $\mathrm{HAl})$ has continued to grow, fuelled by extensive media coverage and growing public concern. As always, the RCPE Hot Topic Symposium delivered a very timely forum for discussion on an area of major importance to medicine, just days after the formal opening of the public enquiry into the Clostridium difficile outbreak at the Vale of Leven Hospital in Scotland.

To highlight the political dimension, Nicola Sturgeon MSP, Deputy First Minister and Cabinet Secretary for Health andWellbeing in the Scottish Parliament, delivered the keynote speech. She set the theme of the talks, describing the long-term challenge of what is currently at the top of the political and health agenda in the National Health Service, and stressed the importance of collaborative working and ongoing commitment in the fight to reduce $\mathrm{HAl}$.

\section{IMPROVING THE QUALITY OF ANTIMICROBIAL PRESCRIBING}

The first session included two charismatic speakers offering their perspectives on this challenging topic. Professor Jan Kluytmans (Professor of Medical Microbiology and Infection Control at VU University Medical Centre in Amsterdam) looked specifically at the simple but inconvenient truth of our increasing antibiotic use causing increasing antibiotic resistance. He showed that by introducing multiple, targeted interventions, including active monitoring and feedback of prescriptions, the hospital-wide use of quinolones was significantly reduced. This change ended the increasing quinolone resistance rate among Escherichia coli.

Dr Andrew Seaton (Consultant in Infectious Diseases, Gartnavel General Hospital, Glasgow) focused on the crucial role of antibiotic prescription in selecting $C$. difficileassociated infection (CDI), among other HAls, as specific antibiotics have been shown to be more likely than others to be associated with CDI. The development of a national strategy through the Scottish Antimicrobial Prescribing Group and local antimicrobial management teams have led to specific restrictions on the four ' $c$ ' high-risk antibiotics (co-amoxiclav, ciprofloxacin [and other quinolones], clindamycin, cephalosporins). In Greater Glasgow and Clyde this has shown a substantial reduction in CDI.

\section{CLOSTRIDIUM DIFFICILE}

This session provided a global perspective on CDI, beginning with Dr Mark Miller (Chair of Infection Prevention and Control, Jewish General Hospital, Montreal) sharing his experience following a major hospital outbreak in Canada. With an incidence of 22.5 per I,000 admissions, and a 30-day attributable mortality rate of $6.9 \%$, the media and public focus on this outbreak was intense. ${ }^{2}$ Here the concentration was on reducing patient acquisition by stringent infection prevention and control, with immediate isolation being pivotal. Encouragingly, despite an infrastructure similar to that of Scotland, with old buildings and limited isolation facilities, control was still achieved rapidly.

Professor John Coia (Director of the Scottish Salmonella, Shigella and Clostridium difficile Reference Laboratory, Glasgow) gave an update on the situation in the UK, describing the large regional variation in both strain types and the rates of decline of CDI. He highlighted that CDI caused by any strain should be a cause for concern, and the need for enhanced surveillance continues. Outcomes, and not just rates, will continue to be important.

The epidemiology was taken a step further by Dr Ed Kuijper (Medical Microbiologist, Leiden University Medical Centre), who looked across Europe at the emergence of new strains, particularly 078 , and also showed how distribution varied greatly. ${ }^{3}$ He explained that $C$. difficile toxin has been found in the diarrhoeal stool samples of animals, and added that concerns about its potential association with antibiotic use in animals and agriculture merit attention. ${ }^{4}$

\section{INFECTION CONTROL}

Discussing this topic more broadly, the third session focused on the role of government targets for HAl rates and screening, and we were reminded that bacteria are not only confined to the four walls of the hospital. Professor Brian Duerden (Inspector of Microbiology and Infection Control, UK Department of Health) expressed his wish for creating a safe environment first and foremost, and delivering care within that environment - a striking reversal of current thinking in which we take measures to prevent infection as a necessary afterthought. 
A 'no-tolerance' policy towards avoidable infections was the foundation for targets set to reduce methicillin-resistant Staphylococcus aureus (MRSA) and CDI rates. In England these targets have been achieved through increased pressure upon management by creating accountability.

Professor Jacqui Riley (Consultant Nurse Epidemiologist, Health Protection Scotland) gave an overview of interim results from the Pathfinder Study, the MRSA screening pilot due to be rolled out across Scotland.This pilot study involved screening patients who were admitted to hospital, or due to be admitted for elective procedures, and then giving decolonisation treatment to those patients who were MRSA-positive. Various factors were associated with colonisation, and those patients colonised with MRSA were 15 times more likely to develop infections with MRSA during their stay. ${ }^{5}$ The challenge of decolonisation and isolation was only achieved in half the colonised patients - short lengths of stay and MRSA test turnaround times were contributory factors.

The reminder that bacteria are ubiquitous was demonstrated by Professor Peter Hawkey (Professor of Clinical and Public Health Bacteriology and Consultant Microbiologist, University of Birmingham and the Health Protection Agency), who explained how the problem of multi-resistance in Gram negatives is increasing, without doubt driven by human antibiotic use. He pointed out, however, that the use of antibiotics in both veterinary and agricultural quarters and the use of detergents also need to be addressed.

\section{THE FUTURE}

This final session concluded with a whirlwind look into what the future holds. Professor Hilary Humphreys (Professor of Clinical Microbiology and Head of
Department, Royal College of Surgeons of Ireland) gave an insight into how new technologies are being used, primarily in order to achieve compliance with what we already know to be good practice - please see his review on page 16I. New strategies include technology that is able to monitor adherence to hand hygiene and compliance with already implemented care bundles. These are bundles that allow formal documentation of the evidence-based 'best practice' in specific situations, to help achieve uniformity of treatment.

The theme of implementation was echoed by Dr Peter Christie (Consultant in Public Health Medicine, NHS Quality Improvement Scotland). Within Scotland, Dr Christie is striving for the active engagement of health professionals with a tailored, multifaceted approach, where audit and positive feedback lead to change. The aim is to achieve a measurable improvement by 2012 .

\section{TAKE-HOME MESSAGE}

The recurring message of the day's speakers was surprisingly positive. Importantly, the control and reduction of $\mathrm{HAl}$ are achievable, despite the numerous difficulties described. It requires a rigorous back to basics' infection control policy and extensive guidelines and protocols on the management of infections and antimicrobial usage. If these are implemented and strictly adhered to, HAls are controllable. As a trainee, I was left with the feeling that the future can be brighter. Everybody working in healthcare needs to accept responsibility for reducing $\mathrm{HAl}$, and to see this as part of our duty of care. We are not being judged, but offered an opportunity to change the way we practise so that ultimately, as intended, we do no harm.

\section{REFERENCES}

I Willemsen I, Cooper B, Kluytmans J et al. Improving quinolone use in the hospital using a bundle of interventions. (Submitted for publication.)

2 Loo VG, Poirier L, Miller MA et al. A predominantly clonal multiinstitutional outbreak of Clostridium difficile-associated diarrhea with high morbidity and mortality. N Engl J Med 2005; 353:2442-9. doi:I0.1056/NEJMoa05I639

3 Kuijper EJ, Barbut F, Brazier JS et al. Update of Clostridium difficile infection due to PCR ribotype 027 in Europe, 2008. Euro Surveill 2008; I3:pii: 18942.

4 Clooten J, Kruth S, Arroyo L et al. Prevalence and risk factors for Clostridium difficile colonization in dogs and cats hospitalized in an intensive care unit. Vet Microbiol 2008; 129:209-14. doi:10.1016/j. vetmic.2007.II.013

5 Health Protection Scotland. NHS Scotland MRSA Screening Pathfinder Programme: interim report. Edinburgh: Health Protection Scotland; 2009. 